\title{
QUANDO A ARTE E A INFÂNCIA CHAMAM PRA DANÇAR A CIÊNCIA: INVENÇÕES, AFETAÇÕES E EQUILIBRISMOS
}

\author{
WHEN ART AND CHILDHOOD CALL SCIENCE TO DANCE: INVENTIONS, \\ AFFECTIONS AND BALANCING ACT
}

\author{
CUANDO EL ARTE Y LA INFANCIA LLAMAN A LA CIENCIA A BAILAR: \\ INVENCIONES, AFECTACIONES Y EQUILIBRISMOS
}

Élida Santos Ribeiro ${ }^{1}$

Laís de Paula Pereira ${ }^{2}$

\begin{abstract}
Resumo: Numa perspectiva freiriana de que a leitura da palavra é tributária da leitura de mundo, ou das leituras de mundos possíveis, os olhares sobre a vida fundam também modos de conhecer. A produtividade constituída por um modo capitalístico de operar, conhecer e se relacionar atravessa as mais diversas esferas da vida, priorizando metas e resultados em detrimento dos processos e do sentido. Ao pensar a educação, desde a primeira infância, as metas geralmente determinam como e o que se deve conhecer, fazer, ser. O que busca escapar desses padrões é considerado erro - desviando das Grandes Narrativas em sua ciência maior. Dessa maneira, este trabalho busca investigar como a infância e a arte contribuem para interpelar o funcionalismo moderno, a ciência maior, o tempo produtivo e a postulação de verdades estabelecidas. A partir de relatos, recortes fotográficos, poesias e diálogos teóricos, esses escritos ensaísticos propõem interrogar: como o paradigma do erro-acerto institui infâncias e mundos? Como o funcionalismo moderno se cruza com as processualidades da infância? E como a infância e a arte trabalham nas fissuras abertas, desconcertando o que se quer certo e conformado, atuando como antiferramentas? Entende-se, aqui, que o espanto, a invenção, e as perdas de tempo que a arte e a infância carregam consigo traem a funcionalidade das metas, abrem-se à errância e a uma outra política da educação.
\end{abstract}

Palavras-chave: Erro; infância; arte

Abstract: In a freirian perspective that reading the word is a tributary of reading the world, or readings of possible worlds, the points of view about life also found ways of knowing. Productivity constituted by a capitalistic way of operating, knowing and relating crosses the most diverse spheres of life, prioritizing goals and results at the expense of processes and meaning. When thinking about education, from early childhood, goals generally determine how and what one should know, do, be. What seeks to escape these patterns are considered mistakes - deviating from the Grand Narratives in their greater science. Thus, this work seeks to investigate how childhood and art contribute to questioning modern functionalism, greater science, productive time and the postulation of established truths. Based on reports, photographic clippings, poetry and theoretical dialogues, these essay writings propose to question: how does the wrong-right paradigm institute childhoods and worlds? How does modern functionalism intersect with the processualities of childhood? And how do childhood and art work in open fissures, disconcerting what is wanted right and conformed, acting as anti-tools? It is understood, here, that the amazement, the invention, and the waste of time

\footnotetext{
${ }^{1}$ Universidade Federal do Rio de Janeiro.

${ }^{2}$ Universidade Federal Fluminense.
} 
that art and childhood bring with them betray the functionality of the goals, opening up to wandering and to another education policy.

Keywords: Mistake; childhood; art.

Resumen: En una perspectiva freiriana de que la lectura de la palabra es un afluente de la lectura del mundo, o la lectura de mundos posibles, las visiones sobre la vida son también la base de las formas de conocer. La productividad constituida por una forma capitalistica de operar, conocer y relacionarse atraviesa los más diversos ámbitos de la vida, priorizando metas y resultados a expensas de los procesos y el sentido. Al pensar en educación, desde la primera infancia, las metas generalmente determinan cómo y qué se debe saber, hacer y ser. Lo que busca escapar de estos patrones se considera un error: desviarse de las Grandes Narrativas en su gran ciencia. Así, este trabajo busca investigar cómo la infancia y el arte contribuyen al cuestionamiento del funcionalismo moderno, la ciencia mayor, el tiempo productivo y la postulación de verdades establecidas. A partir de reportajes, recortes fotográficos, poesía y diálogos teóricos, estos ensayos se proponen cuestionar: ¿cómo instituye el paradigma del erroracierto las infancias y los mundos? ¿Cómo se cruza el funcionalismo moderno con los procedimientos de la infancia? ¿Y cómo la infancia y el arte funcionan en fisuras abiertas, desconcertando lo que se quiere correcto y conformado, actuando como anti-herramientas? Se entiende, aquí, que el asombro, la invención y la pérdida de tiempo que traen el arte y la infancia traicionan la funcionalidad de las metas, abriéndose al extravío y a otra política educativa.

Palabras clave: Error; infancia; arte.

\section{Introdução}

Aurora brincava na areia. Era um fim de tarde na praia, num vilarejo de pouco mais que 4.000 habitantes, em meados de 2021. Tinha ao seu lado balde, pás e colheres grandes disponíveis, um daqueles kits prontos de praia. Mas preferiu encher o balde utilizando um garfo. Era um garfo descartável, achado na rua, pelo menos três vezes menor que as outras ferramentas. Um garfo, com buracos no lugar da concavidade inteiriça adequada para conter. Mesmo assim, preferiu transferir a areia de um lugar a outro com aquela. Era uma antiferramenta. Não era indiferença que movia sua escolha, ela trabalhava com diligência e envolvimento. É que a experiência importava mais do que o resultado. Resultado?

Começamos com esse pequeno relato, que aconteceu com uma de nós há pouco, para ancorar o lugar da infância e da arte como antiferramentas. Num mundo hipermoderno em que a desregulamentação econômica, a flexibilização das leis trabalhistas e a mercantilização da própria vida (GALLO, 2006) apoiam-se na produtividade levada ao extremo, "batemos metas" nas diversas instâncias da vida. Os resultados engolem o percurso e perguntamo-nos se existe vida entre uma meta e outra. Ou melhor, tem existido um "entre"? Para atendermos as metas e chegarmos aos resultados esperados (ou exigidos), cada objeto, cada ação, cada encontro, deve ser útil. E como afirma o líder indígena Ailton Krenak (2020) já no título de sua obra, “A vida não é útil". Essa afirmativa, disruptiva de uma lógica que sustenta o projeto moderno capitalista - aquele enraizado e desenvolvido no esteio do funcionalismo -, nos leva a pensar que temos sido capazes de produzir de tudo um pouco, mas vivido (n)uma escassez de vida.

O capitalismo quer nos vender até a ideia de que nós podemos reproduzir a vida. Que você pode inclusive reproduzir a natureza. A gente acaba com tudo e depois faz outro, a gente acaba com a água doce e depois ganha um dinheirão dessalinizando o mar, e, se não for suficiente para todo mundo, a gente elimina uma parte da humanidade e deixa só os consumidores (KRENAK, 2020, p. 66). 
Marshal Sahlins, antropólogo estadunidense, em seu texto A tristeza da doçura, ou a antropologia nativa da cosmologia ocidental (2004), aponta que a fundamentação e a sustentação do sistema capitalista estão baseadas na eterna insuficiência humana, a qual nos coloca sempre em busca de algo que satisfaça necessidades - e na ideia de tirarmos "a máxima satisfação de meios que estão sempre aquém de nossas necessidades" (SAHLINS, 2004, p. 567), onde mesmo as relações sociais têm sido estabelecidas para suprir uma carência ou por ser vantajoso. Sobre-vivemos, portanto, a serviço do capitalismo produtivo, sendo poucas as brechas, as fissuras, os "entre" que nos restam diante dos "sacrifícios necessários" em prol das necessidades criadas e do crescimento econômico imposto.

Contudo, o caráter insustentável desse desenvolvimento já é sabido, se tornou um conhecimento comum. Diante disso, a filósofa e historiadora Isabelle Stengers (2015) se reporta a um fato: temos que "questionar a capacidade daquilo que hoje se chama de desenvolvimento de responder aos problemas" (p. 8). Temos, ainda, complementa a autora, que exigir muitas coisas dos protagonistas que hoje definem o que pode e o que não pode, o que está certo e o que está errado, o que é possível e o que não é possível. Mas não só isso. Enquanto lutamos contra aqueles que insistem em nos contar uma história única, que reforça as Grande Narrativas, devemos assumir o que agora sabemos e criar desvios para as narrativas que se pretendem hegemônicas.

Mas como questionar o que se apresenta como fato? Como colocar em xeque a história única que nos contam há tempos? Será possível deixarmos de lado as ferramentas reconhecidas pela sua utilidade e criarmos antiferramentas? Quem ousaria inquirir a verdade atribuída aos conhecimentos científicos (sem, com isso, tornar-se um negacionista)? Como transver o que se apresenta como realidade dada? Não temos a intenção de dar respostas prontas, o que queremos com esses questionamentos é suspender o dado. É abrir fissuras no nosso pensamento moderno ocidental e nos conhecimentos que temos incutido nos mais diversos espaços de aprendizagem. Criar linhas de fuga e romper com as ciências financiadas por grandes empreendimentos e que, por tal razão, "é relativamente certo que as respostas que os cientistas hão de propor não nos permitirão evitar a barbárie" (STENGERS, 2015, p. 19).

Muitos dos conhecimentos produzidos pela ciência maior ${ }^{3}$ têm como pano de fundo o lucro, e não importa em detrimento de que. Tomamos como exemplo os Organismos Geneticamente Modificados (OGM) e patenteados e as questões levantadas por Stengers (2015) em seu livro "No tempo das catástrofes". Postos como um novo modo de produção agrícola e uma possível resposta para o desafio da fome, estes foram apresentados por especialistas como "factibilidade" de uma inovação a serviço do inelutável, ou seja, do progresso. De acordo com a autora, esses especialistas trabalhavam sobre o dossiê preparado pela indústria, realizando experimentos de risco, mas mantendo o slogan "a ciência a serviço de todos". Contudo, na Europa, o "acontecimento OGM" (p. 27) foi questionado por uma grande parcela da população e o governo francês "traiu" a ciência cedendo aos medos irracionais, às superstições, de um povo que não possuía a competência dos especialistas para julgar e opinar sobre tais acontecimentos. Esse evento suscitou uma verdadeira "lição das coisas" e a emergência de narrativas que abrem tal acontecimento para novas conexões, outras práticas de produção que a modernização havia condenado (STENGERS, 2015). Esse é apenas um dentre os milhares de exemplos que poderíamos citar e que traz à tona o debate a respeito da ideia de "verdade" e "conhecimento universal" produzidos e difundidos pela ciência maior - e consequentemente de mentira, superstição e irracionalidade. Uma ciência que se pretende única,

\footnotetext{
${ }^{3}$ O que chamamos aqui de "ciência maior" é aquela que se constrói e institui como modelo a ser seguido (GALLO, 2013). Uma ciência concebida como única forma legítima de acesso aos conhecimentos do mundo, sendo, portanto, intolerante perante outras formas de saber que ela mesma carrega (CHAVES, 2013).

4 "Leçon de choses", método pedagógico aplicado na França no século XIX, pelo qual as crianças aprendem a partir da observação direta e do pensamento intuitivo (STENGERS, 2015, p. 30).
} 
válida para todas e todos, independentemente dos riscos que pode gerar, do contexto social em que se encontra, do credo, da raça, do gênero e da idade das pessoas que são direta e indiretamente afetadas por ela. Do lugar de onde miramos, as metas, a funcionalidade e a busca da verdade caminham de mãos dadas instituindo modos de ser e conhecer no mundo.

[...] percebemos que os regimes de verdade acerca do mundo e suas soluções se assentam na escassez, pois as suas saídas não miram a diversidade como potência. Assim, haveremos de assumir como resposta responsável o atravessamento e a transmutação das lógicas intransigentes e desencantadas contrárias à diversidade (RUFINO, 2019, p. 26).

Escrever este texto é uma tentativa de trazer encantamento; transgredir esses regimes de verdade mantidos pelo colonialismo e que seguem perpetuando injustiças cognitivas e destituição ontológica dos seres, atacando a diversidade que compõe o mundo (RUFINO, 2019). E para uma virada do conhecimento "Temos que parar de nos desenvolver e começar a nos envolver" (KRENAK, 2020, p. 24), tal qual as crianças e a arte têm feito com suas antiferramentas. Para tanto, abrimos espaço para a suspensão dos currículos-saberes-fazeres acostumados, convidando a infância e a arte para interpelarem o tempo produtivo, as metas, as utilidades e o estabelecimento das dicotomias erro-acerto e verdade-invenção. A partir de relatos, recortes fotográficos, poesias e diálogos teóricos, esses escritos ensaísticos propõem interrogar: como o paradigma do erroacerto institui infâncias e mundos?, como o funcionalismo moderno se cruza com as processualidades da infância? e como a infância e a arte como antiferramentas trabalham nas fissuras abertas, desconcertando o que se quer certo e conformado?

\section{A infância como antiferramenta - desacostumando o erro-acerto}

Outro dia, num parque, um menino brincava quando o pai o interpelou: - Vai lá! Sobe no escorrega! - de forma bruta, quase a ordenar. O filho se nega a atendê-lo e continua entretido em sua brincadeira, quando o pai insiste: - O que você está fazendo?? - ao que o filho responde dizendo que estava juntando pedras. O pai, indignado, pergunta-lhe por que estava fazendo isso! (...).

Por que ainda perdemos tempo sendo crianças? Brincar não serve para nada, imaginar tampouco, já que se tem de passar pela infância, que pelo menos se aproveite o tempo para treinar, para melhorar o desempenho no escorrega ou no futebol. Afinal, "o que você vai ser quando crescer?". O filósofo e escritor indígena, Daniel Munduruku (2017), na conversa “O ato indígena de educar(se)" realizada na $32^{\mathrm{a}}$ Bienal, levanta questões a respeito dessa pergunta que comumente fazemos às nossas crianças. Ele nos conta que na etnia indígena Munduruku esse questionamento não é feito às crianças, e isso se dá por um motivo muito simples: "as crianças não serão nada, porque elas já são tudo o que precisam ser, ou seja, são crianças". Ele ainda nos provoca ao dizer que cabe a nós, adultos, darmos as possibilidades para que as crianças sejam plenamente crianças. Diante dessa convocação, nos perguntamos: estaríamos dando as possibilidades - temporais, espaciais, físicas, emocionais, intelectuais - às nossas crianças de criarem suas antiferramentas ou seguimos investindo na lógica produtivista que parece ser o motor das nossas engrenagens? 


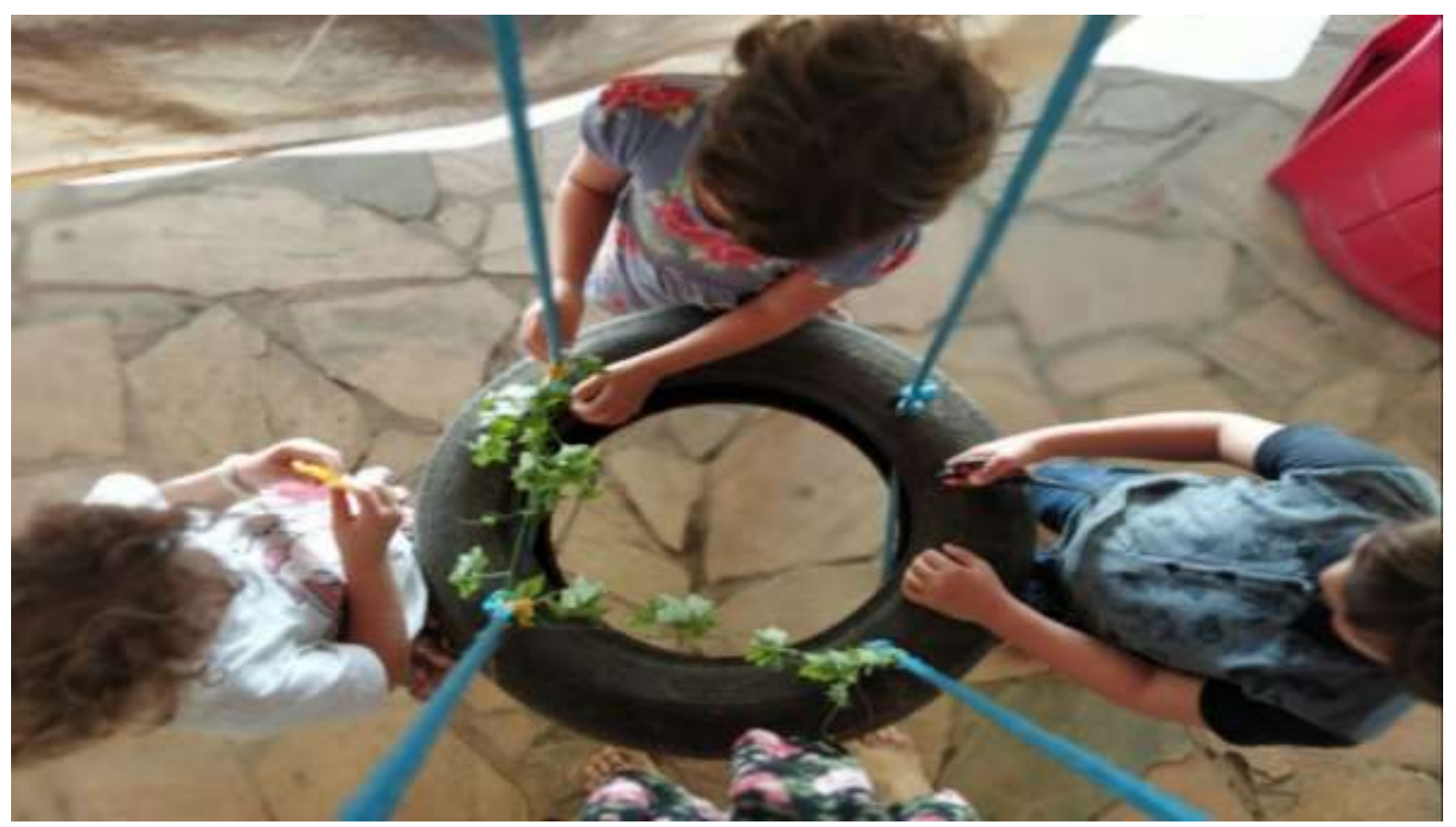

Figura 1: Tecer desimportâncias - Fonte: arquivo pessoal das autoras

Vale ressaltar que a infância não está tomada, ainda, por essa lógica de produção. Os resultados e os processos, para uma criança, misturam-se como terra e água. O resultado é a própria experiência, está na ampliação de sua percepção de mundo, de sua presença. A infância, resistindo às metas externas, reinventa o mundo, abre frinchas numa lata d'água para vê-la cair. Mas, logo adiante, o certo e o errado ensinam a ela que a lata serve para carregar água; que serve para levar água de um ponto ao outro; serve. Ensinam que melhor ainda é chegar no tal ponto logo, na frente, antes de.

Num dia de sol, num passeio no parque com Aurora, havia uma criança muito pequena pedalando uma bicicleta sem rodinhas. Chamava a atenção a desenvoltura da criança, mas logo a mãe assumiu protagonismo na cena: começou a correr à frente da criança, fazendo zigue-zagues entre as árvores do parque, chamando pela criança, na postura de uma treinadora. Alguns instantes depois, sentaram-se ambos no trenzinho de madeira que há no parque e a mãe pôs-se a perguntar:

- Que forma é aquela? Ali, no painel do motorista. Hein? Qual é aquela forma? Não lembra? Você sabe!! Retângulo? Não, quadrado! - E seguiu explicando as diferenças entre as formas geométricas durante quase todo o tempo em que estiveram no trem. Depois, em conversa com a mãe, ela diz que a criança tinha somente três anos. Cabe lembrar que estávamos num parque...

Estamos inseridos num mundo em que os resultados se sobrepõem aos processos: andar de bicicleta, mesmo aos três anos, não pode resumir-se apenas a uma brincadeira, um divertimento, uma experimentação corporal. "Não há tempo a perder! O mundo lá fora é muito competitivo e precisamos sair na frente." Cada oportunidade deve ser aproveitada para aprender algo novo, para saber mais. Nem o brinquedo escapa às representações intelectualizantes: o trem, longe de transportar a um lugar de invenção, de criação de enredos, lugares e aventuras, passa a servir de instrumento para treinar o olhar, para aprender um conceito fechado.

Quadrado.

Como educadoras(es), passamos horas a fio ensinando para que serve e como deve ser usado. Supomos, certamente, que há uma maneira correta - e, portanto, outras erradas - de fazer algo; em última análise, uma maneira correta de existir. Percorrendo locais com crianças e adultos convivendo, salta aos olhos o domínio da noção de erro (que pressupõe a de acerto ou 
verdade): - o sapato está no pé errado; não suba no escorrega pela frente, a escada é lugar por onde você deve subir; não balance com a barriga, o jeito certo é sentado; a bola não é para colocar a mão, é para chutar. Chuta! Vai! Com o pé! Isso.



Figura 2: Desver ferramentas ou Criar antiferramentas - Fonte: arquivo pessoal das autoras

A infância já configura, em si, uma ameaça à ordem estabelecida - vide o esforço que os outros - não infantes - fazem para conter toda essa efusividade. A imaginação já transgride a verdade materializável: o mundo é reinventado a cada brincadeira, as funções são trocadas, a cadeira vira carro, desvira em trampolim e, (...) Desconectados da plasticidade do mundo, os adultos, quando tentam se aproximar, precisam dizer para suportar: "ah, essa areia é uma farofa, mas de mentirinha, hein, não é pra comer não!". O que não tem o desígnio que nos acostumamos a atribuir deixa, automaticamente, de ser verdade. Não vale como reinvenção do mundo, é uma insuficiência, uma ingenuidade de alguém que ainda não sabe a verdade e os conceitos correspondentes.

No livro África ensinando a gente (FREIRE, 2011), Alda do Espírito Santo, escritora e poeta angolana, conta um episódio passado com sua afilhada: a menina chega, um dia, em casa e relata sua indignação ao escutar da professora que em São Tomé e Príncipe não havia frutos. Segundo a professora - europeia -, frutos eram peras, uvas, maçãs. O que a professora dizia, em sua atitude colonizadora, é que o que havia ali naquelas terras africanas era outra coisa, não eram "frutas verdadeiras", "frutas oficiais". Mesmo de forma não tão explícita quanto no referido episódio, a educação formal vem colonizando saberes, emoções e vontades. Ao estabelecer como determinada história ou fenômeno serão contados, interpretados, e tratar conteúdos como verdades, fatos imóveis, instauramos mundos. Convencemos.

Como educadoras(es), ao estabelecermos - ou nos rendermos a - conteúdos universais e fixos, quando entendemos que a função da escola se limita a, justamente, oferecer verdades e ferramentas, de modo a preparar a criança e a(o) jovem para o que ainda vai chegar - afinal, a vida adulta é a verdadeira vida, tudo que vem antes é mera preparação -, alienamos progressivamente o potencial inventivo, criador, transformador de mundos e de certezas que pulsa na infância. Quem é que registra, num relatório pedagógico, frases como: "Maria tem a habilidade de parar de repente e observar um passarinho tomando banho de areia e notou que, quando a areia recebe água, os castelos crescem mais, como acontece com as plantas."?, ou como: "Ravi ajuda as outras crianças 
a perceberem que dá pra subir pela frente do escorrega e lembra a todos, constantemente, que uma tábua pode ser também jangada e que o silêncio pode ser ouvido se fizermos muita força."?

Desde a educação infantil, o que importa é o instrumental, as ferramentas primordiais: saber escrever as letras do nome, copiar, repetir a ordem dos números, copiar, dizer os nomes das cores e das partes do corpo, copiar, repetir o que foi dito, copiar. O conceito de "prova" como culminância do processo avaliativo endossa esse padrão: padrão de comportamento, padrão de aprendizagem, padrão de respostas. Em todos os casos, há um modelo a ser reproduzido, e o que está fora desse modelo constitui um erro.

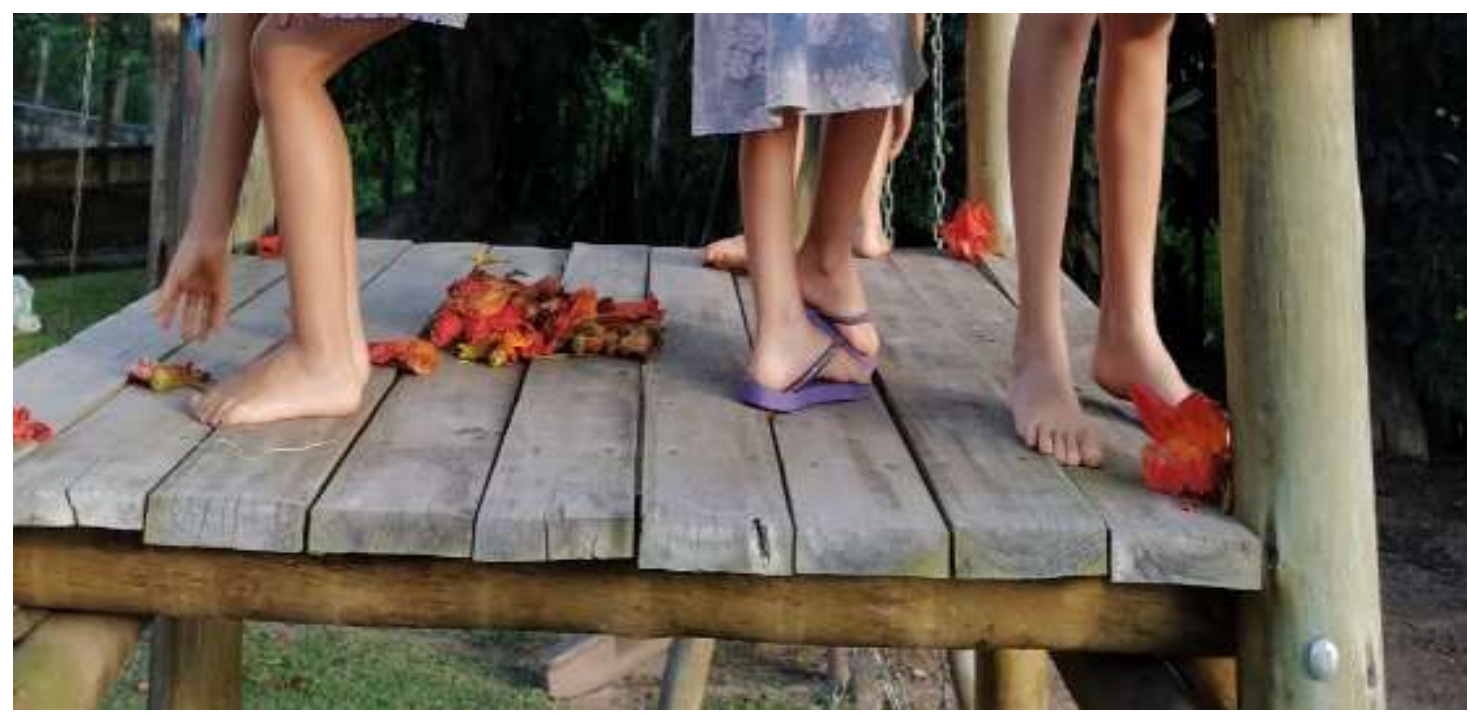

Figura 3: Inventar e imaginar possíveis - Fonte: arquivo pessoal das autoras

Destacamos, sob uma perspectiva freiriana, que a leitura da palavra é tributária da leitura de mundo, ou das leituras de mundos possíveis, entendendo que nossos olhares sobre a vida fundam também modos de conhecer. No livro "Paulo Freire, mais do que nunca: uma biografia filosófica", o filósofo e educador Walter Kohan (2019) nos fala de cinco princípios que podem ser entendidos como razões para ler Paulo Freire. Dentre eles, o princípio da errância.

[O princípio de errância] afirma o duplo valor educacional do errar, no sentido de equivocar-se e do deslocar-se sem determinar previamente o rumo do deslocamento. É algo como confiar nos sentidos políticos do movimento, de entender a vida em constante mudança e a educação em sintonia com essa compreensão da vida. Educar é, nesse duplo sentido, errar, perceber positivamente esses dois movimentos usualmente vistos como negativos para dar lugar à recriação e à reconfiguração que esse duplo errar possibilita. Errar faz sentido porque um outro é possível, o final da história não está nem estará escrito, e esse duplo errar da educadora ou educador abre uma exploração sobre como poderia ser a história mundana ainda por vir. Esse duplo errar também sinaliza um deslocamento, um descentramento, um abrir espaço para os que estão fora, as excluídas, os esfarrapados, as negadas pelo que está dentro. (KOHAN, 2019, p. 214-215).

Admitir o processo de transformação do mundo é, quiçá, adicionar contradição ao que entendemos como certo ou errado: acrescentar errância ao fio da verdade, tornando-o corda-bamba. Equilibrar-nos não como quem chega a um ponto de repouso mas, num equilíbrio dinâmico, como quem dança. A meta não é tão somente chegar do outro lado, mas percorrer com graça, aceitando 
agradecida(o) um prato a mais para pôr a girar. Colocar, assim, o erro em suspensão carrega possibilidades de descolonizar conteúdos, relações, sistemas, saberes, poderes.

\section{$[\ldots]$}

Carrego latas furadas, pregos, papéis usados.

(Ouço harpejos de mim nas latas tortas.)

Não tenho pretensões de conquistar a inglória perfeita.

Os loucos me interpretam.

A minha direção é a pessoa do vento.

Meus rumos não têm termômetro.

De tarde arborizo pássaros.

De noite os sapos me pulam.

Não tenho carne de água.

Eu pertenço de andar atoamente.

Não tive estudamento de tomos.

Só conheço as ciências que analfabetam.

Todas as coisas têm ser?

Sou um sujeito remoto.

Aromas de jacintos me infinitam.

E estes ermos me somam (BARROS, 2010, p. 353).

Luiz Rufino (2019) convoca-nos para a emergência da transgressão, dos escapes aos cânones da educação, problematizando a própria noção de erro: "Exu faz o erro virar acerto e o acerto virar erro" (p. 80). Para o autor, a lógica da conversão habita e estrutura a história brasileira, desde as missões jesuíticas dos primórdios da invasão e colonização portuguesa, que partiam de uma conversão religiosa - e que foram a base das primeiras escolas - mas amplificando esse conceito, passando pela colonização dos saberes, fazeres, corpos e escolarizações, pela difusão de um pensamento único, hegemônico, eurocêntrico, excludente. Essa conversão normatiza, marca e limita nossas formas de ser e de educar. Tudo que está fora desses parâmetros hegemônicos é considerado erro.

por aqui o colonialismo foi amplamente golpeado pelos saberes $\mathrm{e}$ inventividades em cruzo. É nesse sentido que faço estripulias nas frestas, sucateando a "pureza" do que está situado nas "zonas de certezas" da amarração colonialismo/ciência/cristianização. Afinal, meus camaradinhas, Exu é o que substancia o contragolpe à colonialidade, uma rasura, um cruzo e uma traquinagem em tom de feitiço. (RUFINO, 2019, p. 81).

As goteiras abrem-se nas insuficiências dessa colonialidade. É onde a areia cai e dança com o vento. Espalha-se.

$[\ldots]$

O artista é erro da natureza. Beethoven foi um erro perfeito.

Por pudor sou impuro.

O branco me corrompe.

Não gosto de palavra acostumada.

A minha diferença é sempre menos.

Palavra poética tem que chegar ao grau de brinquedo para ser séria.

Não preciso do fim para chegar.

Do lugar onde estou já fui embora (BARROS, 2010, p. 348). 
O educador e escritor brasileiro Rubem Alves (2004) chama a atenção para a possibilidade de transver que as crianças oferecem ao mundo, guardando seus olhos em caixas de brincar, enquanto os olhos acostumados-aculturados-acomodados dos adultos estariam guardados numa caixa de ferramentas. Segundo o educador, embora a física dos olhos possa ser, de forma rasteira, comparada à de uma máquina fotográfica, há algo na visão que escapa à física. Essa potência antiferramenta da infância pode ser assimilada por nós, adultas(os) educadoras(es) ao seu redor, quando aquiescemos em tomá-las como mestras, assim como os poetas (ALVES, 2004).

Ela entrou, deitou-se no divã e disse: "Acho que estou ficando louca (...), faz uns dias, eu fui para a cozinha para fazer aquilo que já fizera centenas de vezes: cortar cebolas. Ato banal sem surpresas. Mas, cortada a cebola, eu olhei para ela e tive um susto. Percebi que nunca havia visto uma cebola. Aqueles anéis perfeitamente ajustados, a luz se refletindo neles: tive a impressão de estar vendo a rosácea de um vitral de catedral gótica. De repente, a cebola, de objeto a ser comido, se transformou em obra de arte para ser vista! E o pior é que o mesmo aconteceu quando cortei os tomates, os pimentões... Agora, tudo o que vejo me causa espanto." (ALVES, 2004, [n. p.]).

Esse espanto frente ao mundo que a arte e a infância oferendam é uma insubordinação ao tempo produtivo: contemplar as camadas de uma cebola, observar uma pedra e ler uma poesia em voz alta configuram perdas de tempo tanto quanto usar um pequeno garfo para encher de areia um balde. Traem a funcionalidade das metas, abrem-se à errância e a uma outra política da educação: "a que não forma, transforma, reforma, mas escuta, acolhe, cuida." (KOHAN, 2019 , p. 215) e que permite, sobretudo, que as crianças habitem o presente.

\section{Considerações errantes}

Prezo insetos mais que aviões.

Prezo a velocidade

das tartarugas mais que a dos mísseis.

Tenho em mim um atraso de nascença.

Eu fui aparelhado

para gostar de passarinhos.

Manuel de Barros, 2018, p. 25

O aparelho de ser inútil estava jogado no chão, quase coberto de limos -

Entram coaxos por ele dentro.

Crescem jacintos sobre palavras.

(O rio funciona atrás de um jacinto.)

Correm águas agradecidas sobre latas...

O som do novilúnio sobre as latas será plano.

E o cheiro azul do escaravelho, tátil.

De pulo em pulo um ente abeira as pedras.

Manuel de Barros, 2010, p. 239 


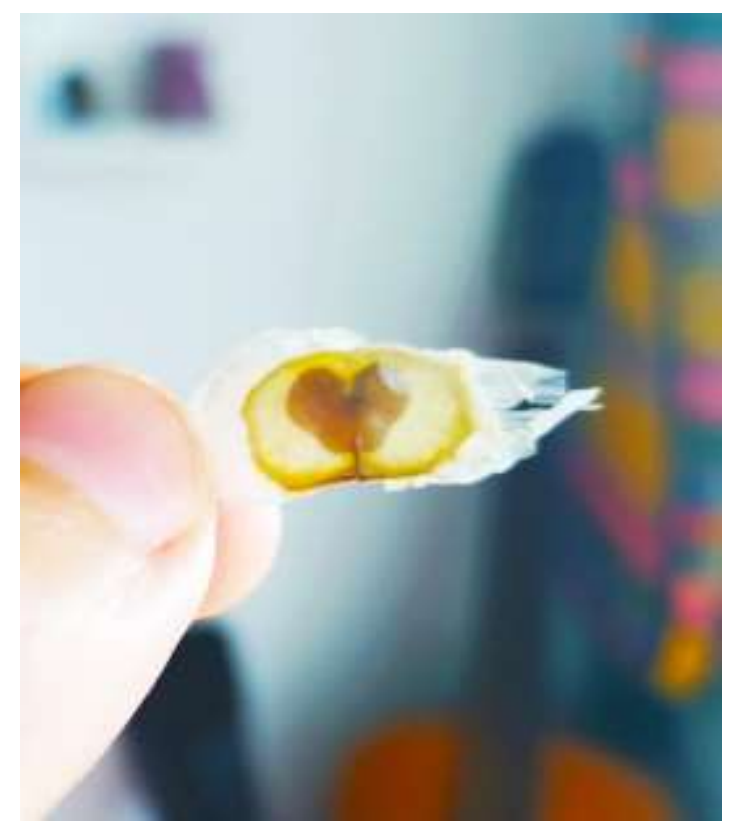

Figura 4: Olhos de brincar - Fonte: arquivo pessoal das autoras

Abrir campo para o erro. Explorar e experimentar trajetos, fissuras, cisões e afetos desde o encontro com a errância. Buscar o menor. Fazer-se no processo. Transgredir. Guardar nossos olhos em caixas de brinquedos. Criar antiferramentas. Descentralizar. Inutilizar. Brincar. Dar possibilidades. Ser possibilidades. Ser verbo infinitivo.

Bem sabemos como é difícil subverter as células do nosso corpo - que às vezes teimam em se acreditar engrenagens -, assim como o que nos habita e se reforça em nós em quase todo encontro. Não obstantes as tentativas de ressignificar o certo-errado, a filha pergunta, depois, se pode "desmoronar" o castelo que construímos, num cruzo entre dois paradigmas: o cuidado com o outro junto da invenção do lugar da palavra desmoronar por um lado e o paradigma do erro por outro ${ }^{5}$. Sobressai a angústia do pedido de permissão para brincar: se poderia derrubar, se poderia estragar, era o que ela queria saber. O brincar, que poderia ou deveria ser um reduto das possibilidades e subversões, onde demolir é tão envolvente como construir, onde o corpo só seguisse o impulso da criação... esse lugar também é tomado pela moralidade do certo e do errado. O que fazer com o dedo apontado sobre nós?

E se suavizarmos as linhas duras que insistem em contornar nossos dedos, nossos corpos, nossos fazeres, saberes e seres? E se transformarmos as linhas retas que nos direcionam para metas, objetivos e resultados pré-determinados em linhas de potências? Como afirmamos no decorrer deste texto com os relatos, os recortes fotográficos, as poesias e os diálogos teóricos tecidos e tramados com os fios - embolados - da infância e da arte, é preciso transgredir os regimes de verdade, a história única que nos contam, o dedo que julga - porque pode, deve e, sobretudo, é autorizado por uma verdade instituída.

Com a intenção de lançarmos um olhar atencioso e generoso às potencialidades dos processos, das invenções e das tantas possibilidades não previstas, exercitamos o alargamento das brechas nas quais as infâncias e a arte têm atuado e fazemos dos nossos equilibrismos antiferramentas brincantes, dançantes e errantes. Desse modo, abrirmos nossas práticas, nossos pensamentos e nossos corpos a uma outra política da educação, disruptiva do paradigma erroacerto e permeada de afetividades e imprevisibilidades

\footnotetext{
5 “Eu queria construir uma ruína. Embora eu saiba que ruína é uma desconstrução” (BARROS, 2010, p. 385).
} 


\section{Referências}

ALVES, Rubem. A complicada arte de ver. Folha de São Paulo, Sinapse, 26 de out. de 2004, [n. p.]. Disponível em: https://www1.folha.uol.com.br/folha/sinapse/ult1063u947.shtml. Acesso em 18 out. 2021.

BARROS, Manoel de. Poesia completa. São Paulo: LeYa, 2010.

BARROS, Manoel de. Memórias inventadas. Rio de Janeiro: Alfaguara, 2018.

CHAVES, Silvia Nogueira. Reencantar a ciência, reinventar a docência. São Paulo: Editora Livraria da Física, 2013.

FREIRE, Paulo. A África ensinando a gente: Angola, Guiné-Bissau, São Tomé e Príncipe. 2. ed. São Paulo: Paz e Terra, 2011.

GALLO, Sílvio. Modernidade/pós-modernidade: tensões e repercussões na produção de conhecimento em educação. Educação e Pesquisa, v. 32, n. 3, p. 551-565, 2006.

GALLO, Sílvio. Em torno de uma educação menor: variáveis e variações. In: REUNIÃO NACIONAL DA ANPED, 36., 2013. Anais... Goiânia. 2013. p. 1-12.

KOHAN, Walter. Paulo Freire mais do que nunca: uma biografia filosófica. Belo Horizonte: Vestígio, 2019.

KRENAK, Ailton. A vida não é útil. Companhia das Letras. São Paulo. 2020.

MUNDURUKU, Daniel. O ato indígena de educar(se): uma conversa com Daniel Munduruku. Bienal de São Paulo, 21 de fevereiro de 2017. Disponível em http://www.bienal.org.br/post/3364. Acesso em: 18 out. 2021.

RUFINO, Luiz. Pedagogia das encruzilhadas. Rio de Janeiro: Mórula Editorial, 2019.

SAHLINS, Marshall. A tristeza da doçura, ou a antropologia nativa da cosmologia ocidental. In: SAHLINS, Marshall. Cultura na prática. Rio de Janeiro: Editora da UFRJ, 2004. p. 563-620.

STENGERS, Isabelle. No tempo das catástrofes: resistir à barbárie que se aproxima. São Paulo: Cosac Naify, 2015.

\section{Sobre as autoras}

Élida Santos Ribeiro. Mestranda em Educação em Ciências e Saúdes pelo Instituto NUTES (UFRJ). Trabalha desde 2010 com Educação, tendo sido a maior parte de sua trajetória na Educação Infantil. De 2011 a 2018 trabalhou em escolas com a metodologia Waldorf. Atualmente, realiza trabalhos de consultoria pedagógica. Formada em Pedagogia Waldorf pelo Centro de Formação Vale de Luz. Curso de Pós-graduação Lato Sensu "Profissionais da escola e práticas curriculares" pela Universidade Federal Fluminense, concluído em 2011. Graduanda 
em Letras pela Universidade Federal Fluminense (via CEDERJ). Graduada em Medicina Veterinária pela Universidade Federal Fluminense (2009). Mãe da Aurora desde 2019.

E-mail: elidasribeiro@gmail.com.

Laís de Paula Pereira. Graduada em Ciências Biológicas (2010), tem mestrado em Educação (2018) e está doutoranda em Educação, todos pela UFF. Foi professora de Ciências pela Seeduc-RJ (2011-2012) e desde 2012 atua como coordenadora de projetos, coordenadora pedagógica e educadora ambiental junto a instituições públicas, privadas e do terceiro setor. Está Mediadora a Distância no curso de Ciências Biológicas pelo CEDERJ/UFRJ desde 2020 e atua junto ao Instituto de Arte TEAR desde 2021. Pesquisa na área de Educação, com ênfase em Educação Ambiental; práticas de conhecimentos, pensamentos e saberes ecológicos menores; comunidades tradicionais; Ensino de Ciências e Biologia; Educação Infantil, Literatura e formação de professores. Integrante do grupo de pesquisa "Entre-mundos: Ecologias, Pedagogias, Culturas”. Mãe da Lila desde 2016.

E-mail: laisbiouff@gmail.com. 